\title{
2016, ano em que o país sofreu um golpe político- institucional, não termina
}

Desirée Guichard Freire, Floriano José Godinho de Oliveira, Guilherme Ribeiro e Leandro Dias de Oliveira

\section{Q OpenEdition}

1 Journals

\section{Edição electrónica}

URL: http://journals.openedition.org/espacoeconomia/2511

DOI: 10.4000/espacoeconomia.2511

ISSN: 2317-7837

Editora

Núcleo de Pesquisa Espaço \& Economia

\section{Refêrencia eletrónica}

Desirée Guichard Freire, Floriano José Godinho de Oliveira, Guilherme Ribeiro e Leandro Dias de Oliveira, « 2016, ano em que o país sofreu um golpe político-institucional, não termina », Espaço e Economia [Online], 9 | 2016, posto online no dia 09 janeiro 2017, consultado o 10 dezembro 2020. URL : http://journals.openedition.org/espacoeconomia/2511; DOI : https://doi.org/10.4000/ espacoeconomia.2511

Este documento foi criado de forma automática no dia 10 dezembro 2020.

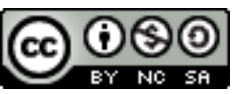

Espaço e Economia - Revista brasileira de geografia econômica est mise à disposition selon les termes de la licence Creative Commons Attribution - Pas d'Utilisation Commerciale - Partage dans les Mêmes Conditions 4.0 International. 


\title{
2016, ano em que o país sofreu um golpe político-institucional, não termina
}

\author{
Desirée Guichard Freire, Floriano José Godinho de Oliveira, Guilherme \\ Ribeiro e Leandro Dias de Oliveira
}

12016 foi um ano especialmente difícil para o Brasil, devido ao inaceitável golpe político e suas inúmeras implicações econômicas, políticas e sociais. O golpe, de fato, acabou determinando o clima e o ritmo do ano, já que envolveu incansáveis e intermitentes manobras institucionais e de mídia que mantiveram as relações políticas e sociais em um estado de convulsão prolongado, dolorido e desagregador.

2 E como parte fundamental das manobras do golpe era a intensificação brutal da crise econômica a partir dos mais variados artifícios, temos também como resultado uma quebra real da economia, envolvendo agora a aceleração do desemprego, a insolvência de estados da federação e de municípios, a dilapidação de serviços e atividades públicas dentre outros aspectos que, conjugados, estão interrompendo e talvez cancelando as perspectivas que de algum modo vinham sendo construídas.

O caráter desses acontecimentos indica que o ano de 2016 não se encerrou e não se encerrará, não só porque seus acontecimentos continuam em franco desdobramento, mas também porque precisamos que a memória viva dos fatos ilumine as lutas futuras.

4 A história de resistência e de luta da Catalunha por independência ilustra com especial beleza a importância do não esquecimento na construção do futuro. A formação histórica da Catalunha como conjunto territorial, cultural, político e jurídico vincula-se ao período medieval, configurando-se, a partir de então, seu sentido de nação. A região foi, ao longo do tempo, objeto de inúmeras tentativas de dominação, mas sua decisiva subordinação a outro Estado deu-se no século XVIII por meio de sua anexação ao Estado monárquico espanhol. Tal anexação, porém, não eliminou dos catalães nem a língua nem o sentimento de nação e a luta por independência, hoje absolutamente revigorada, tem como marco histórico uma brutal derrota ocorrida em 11 de setembro de 1714, na qual, após um prolongado cerco de forças francesas e castelhanas à resistência 
concentrada na cidade de Barcelona, os líderes catalães foram assassinados e o território da Catalunha foi enfim subordinado.

Quem chega à Catalunha, atualmente, no dia 11 de setembro, surpreende-se com o vigor da festa popular que celebra esse dia de derrota. Nota-se, porém, que comemorar a derrota não é exatamente o sentido dado pelos catalães a essa festividade. Para eles, desfraldar bandeiras nas janelas, ir às ruas com seus filhos e relembrar a história é uma forma de fortalecer os laços de solidariedade e de ampliar a compreensão política e os vínculos que alimentam a luta pela independência.

6 Em sentido similar, o dia 14 de abril de 2016 no Brasil deverá ser lembrado com o dia do golpe contra a democracia no Brasil, diante do macabro espetáculo no Congresso Nacional, onde deputados corruptos e réus em inúmeros processos de corrupção votavam pela admissibilidade da cassação de Dilma Rousseff, do Partido dos Trabalhadores, presidenta eleita por mais de 54,5 milhões de votos dos brasileiros, sem que nenhum crime de responsabilidade tenha sido comprovado. Abriu-se ali uma ferida na dignidade do povo brasileiro que não será curada enquanto perdurar o Estado de exceção imposto pela aliança institucional-midiática com a classe dominante brasileira.

7 No dia seguinte ao Golpe, assume um governo interino e ilegítimo, tendo à frente um dos artífices do Golpe, Sr. Michel Temer, e parte dos partidos da antiga base da presidenta, mas que igualmente a traíram e deram suporte ao processo, com o apoio de todas as cúpulas dos partidos derrotados nas urnas.

8 As ações de supressão dos direitos sociais foram imediatas. Aprovação do Projeto de Emenda Constitucional no 241, que altera a Constituição Federal de 1988, com o intuito de congelar as despesas do Governo Federal, determinando que sejam corrigidas apenas pelos índices de inflação, por até 20 anos; aprovação da medida provisória 746/16, que determina a reforma no ensino médio, alterando de forma redutora sua estrutura e mascarando essa redução com uma farsesca flexibilidade da oferta de disciplinas; corte nas verbas de assistência do programa Bolsa Família, projeto de apoio às famílias que vivem em situação extrema de pobreza; e revisão das metas do Programa Minha Casa Minha Vida (PMCMV).

Estes são os grandes marcos jurídicos e programáticos das mudanças regressivas que a partir de então passam a ser engendradas e cujas implicações reais só são debatidas nas redes sociais, pois a grande mídia pouco comenta sobre o assunto e, quando o faz, é para reforçar os pontos de vista conservadores, apresentando como positivas e necessárias medidas que reduzirão brutalmente os direitos e ampliarão o assalto de poucos ao fundo público.

10 Enquanto isto, nas sombras, às vezes nem tanto, é a economia do país que está sendo destruída. E é dela que passamos a nos ocupar nesta breve análise.

11 É inegável que os alvos centrais do golpe, com amplo apoio do grande capital internacional e do governo americano, são: o domínio da Petrobrás, maior empresa brasileira no campo energético e detentora de ampla base tecnológica e de inovações para a produção do petróleo em águas profundas; restringir a atuação da Odebrecht no mercado internacional, diante do domínio que a empresa adquiriu mundialmente e, em particular, na América Latina; e, para alimentar os interesses das frações das classes dominantes internas, desarticular as políticas de distribuição de renda e garantias trabalhistas construídas durante os governos Lula e Dilma. 
12 A Petrobras é uma empresa cujo controle majoritário é exercido pelo Governo da União e, pelo volume de recursos que movimenta - sobretudo após a política do governo Lula de centralizar as contas da empresa, antes descentralizadas nas unidades de refino e de produção -, acabou por ampliar um esquema histórico de corrupção na companhia por parte de diretores e políticos inescrupulosos, que usaram a empresa com fins eleitorais e de enriquecimentos ilícitos. Tal fato começou a ser investigado ainda no primeiro mandato da presidenta Dilma, sob a direção da ex-Presidente da Petrobrás Graça Foster. Mas, a partir de abril de 2014, antes de obter resultados mais significativos nas investigações, a corrupção na empresa tornou-se o mote do Ministério Público Brasileiro para atacar o mandato da presidenta Dilma, seis meses antes das eleições presidenciais. 0 objetivo era desgastar a presidenta e impedir que ela vencesse as eleições, mas isso não ocorreu e, como se sabe, Dilma Rousseff se reelegeu com 54.501.118 votos. A partir daí, uma exposição sem precedentes da empresa foi realizada pelo Ministério Público, em nítida associação com as seis famílias brasileiras que controlam 95\% da mídia no Brasil e com as forças mais reacionárias da classe dominante, buscando-se inviabilizar o governo e desestabilizar a própria empresa.

Mas, por que desestabilizar a empresa?

14 Para criar as condições para retomar o processo de privatização da Petrobras, defendido, e já com acordos internacionais firmados para que isso acontecesse, pelas forças políticas que apoiavam a candidatura do PSDB à presidência. Duas coisas incomodavam muito às empresas petrolíferas mundiais e às indústrias multinacionais que dispõem das tecnologias para as atividades de extração do petróleo. Primeiro, o denominado "contrato de partilha", que garantia à Petrobrás, ou seja, ao Brasil, o direito sobre $30 \%$ da exploração do petróleo nos poços licitados no mercado. Tal dispositivo garantia o controle e/ou presença da empresa em todos os campos petrolíferos brasileiros. Segundo, no campo da produção de máquinas e equipamentos para as atividades exploratórias, o "conteúdo local", ou seja, a necessidade de que os equipamentos comprados pela Petrobrás tenham uma proporção que varia entre $40 \mathrm{e}$ $60 \%$ de componentes produzidos no Brasil.

Não foi por acaso que a Petrobras, logo após o impeachment da presidenta Dilma, sob a presidência no Sr. Pedro Parente - ex-ministro do Governo de Fernando Henrique Cardoso, apoiado diretamente pelo agora Ministro das Relações Exteriores José Serra iniciou um amplo processo de negociações e "venda de ativos" da Petrobrás. Em paralelo, o Congresso Nacional votou a revogação das medidas restritivas ao capital internacional e eliminou os dispositivos constitucionais que garantiam tanto o "contrato de partilha" quanto as cláusulas de "conteúdo local". A partir de então, evidentemente, os ataques midiáticos à empresa cessaram e a exposição nacional e internacional da Petrobrás pelo Ministério Público, propagadora da ideia de que a empresa "fora destruída pela corrupção", do dia para noite, parou. O resultado é surpreendente e revela a falsidade dos argumentos impostos antes do processo de impeachment, pois a Petrobrás, de empresa falida como era apresentada, terminou o ano de 2016 com a maior valorização já vista no meio empresarial, como revela Pessanha (2017).

16 A Petrobras saiu de um valor de R\$ 101 bilhões no final de 2015, para a bagatela de R\$ 209 bilhões no final de 2016. Um aumento recorde, em toda a história da Bolsa de Valores no Brasil com 106\% de aumento de valor num único ano. Sim, vai ter quem 
negue o script traçado na trama midiático-jurídico-parlamentar e realizado ao longo do ano. Porém, os fatos são reais ${ }^{1}$.

Outro aspecto revelador foi o tratamento diferenciado dado à empresa Odebrecht pela força tarefa do Ministério Público que, a nosso ver, foi movido por uma dupla intencionalidade: por ser a empresa líder do setor de construção civil e imobiliário no Brasil, a companhia poderia ser um bom local para a obtenção de provas materiais contra Lula e o PT, partido de Dilma Rousseff. Assim, como havia interesse em enfraquecer a Odebrecht e convicções de que por meio de suas delações se poderia chegar ao Lula, não mediram o peso da mão sobre ela. Ocorre que a empresa também tinha suas estratégias e respondeu à indução de delação contando tudo, não apenas entregando seletivamente o que o Ministério Público queria. Daí a situação atípica: como as outras empresas fizeram algum jogo para se safarem, não precisaram expor tudo o que fazem, parecendo que apenas pecaram em "pequenas corrupções"2.

Por outro lado, o ataque à empresa serviu a interesses internacionais. Afinal, a Odebrecht possui atualmente uma grande diversificação em ramos inovadores, como o de energia nuclear e naval, com presença em mais de 44 países. 0 que causa mais espanto nesse processo da Odebrecht é que o processo contra a empresa tem sido entregue às autoridades de todos os países onde a empresa atua e isso está levando à suspensão dos contratos em curso. Não se conhece, na história empresarial dos países desenvolvidos, registros de denúncias contra suas próprias empresas por nenhum governo.

O caso de corrupção nos empreendimentos da Petrobrás envolveu todas as grandes empreiteiras brasileiras, sendo que todos os principais dirigentes dessas companhias foram presos e condenados pela Justiça Federal, mas receberam o benefício da liberdade com restrição de circulação, devido à cooperação com a justiça, por força de um procedimento de delação induzida de seus crimes. A exceção foi justamente o presidente da Odebrecht, que continua preso, e os cerca de 70 dos diretores da empresa, que, a partir de prolongada detenção estão sendo obrigados a realizar a tal "delação premiada".

20 Para completar a trama, o Congresso Nacional está brindando os brasileiros com uma ampla reforma trabalhista que altera substancialmente as regras da CLT (Consolidação das Leis Trabalhistas), na qual são estabelecidos os diretos dos trabalhadores e se garante o sistema de proteção social, iniciado no Governo de Getúlio Vargas e aprofundados durante os governos Lula e Dilma. E a Proposta de Emenda Constitucional que institui a reforma da Previdência Social, certamente, é o marco desse desmonte. $O$ projeto impõe a idade mínima de 65 anos e 49 anos de tempo de serviço com contribuição à Previdência para se conquistar a aposentadoria.

21 Na virada do ano já se evidenciou o quadro de regressão nos direitos dos trabalhadores. Uma das políticas de promoção da justiça social no Brasil vinha sendo realizado por meio de uma melhor distribuição de renda, cujo aumento real do salário mínimo recebido pelos trabalhadores era uma de suas estratégias. Contudo, conforme noticiado pelo Portal G1 das organizações Globo, podemos constatar a regressão também na política de distribuição de renda no país ${ }^{3}$. 


\section{Sem ganho real \\ Pela primeira vez em 15 anos, reajuste do salário mínimo só repõe a inflação}

\section{ISalário mínimo, em R\$̣ o-Aumento real, em \%}

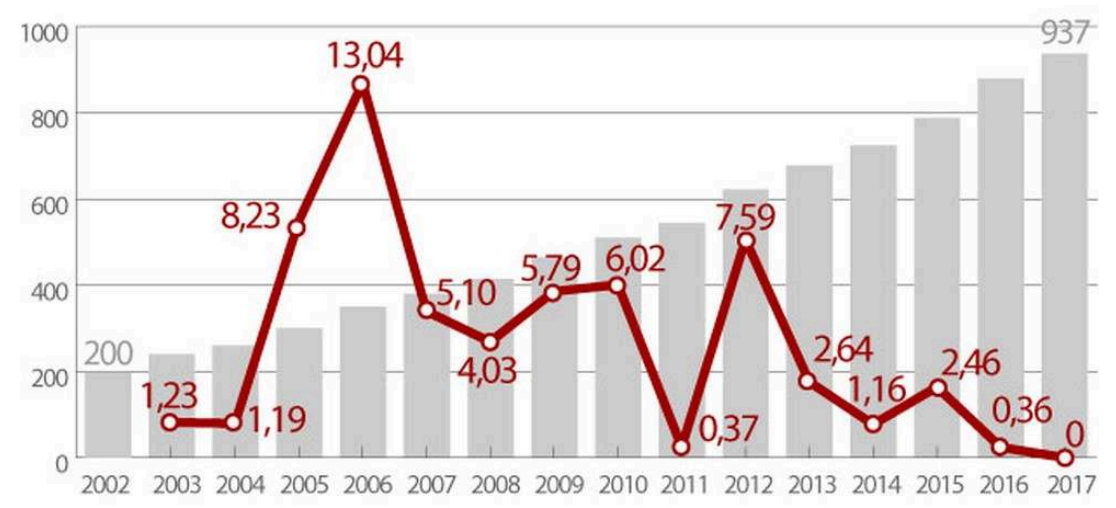

G

Infográfico elaborado em: 02/01/2017

Todos esses fatos reforçam a tese de que 2016 é um ano que não terminou. Primeiro, porque os fatos que nele tomaram corpo permanecem ativos e centrais, produzindo uma espécie de prolongado presente cujos desfechos ainda não se pode apreender com a necessária clareza. Mas também porque a compreensão e o enfrentamento das mudanças em curso exige que não esqueçamos o passado, pois necessitamos de suas memórias para construir o futuro. Nesse sentido, é um ano que deve ficar em aberto na lembrança de todos, para que possa ser revivido em cada luta dos movimentos sociais e dos trabalhadores contra o assalto que o país sofreu, até que possamos apagar todo o mal que foi feito por aqueles que urdiram um golpe político institucional que degradou a economia, as políticas sociais, e, sobretudo, decretou o fim da democracia no Brasil. Os trabalhadores brasileiros não podem admitir que a história seja apagada, e acabe sendo contada pela ótica daqueles para quem o Brasil não passa de um recurso útil para a manutenção de suas posições e o crescimento dos seus negócios.

\section{NOTAS DE FIM}

1. Consultar : http://www.robertomoraes.com.br Blog de Roberto Moraes Pessanha, Professor Doutor do Instituto Federal de Educação, Ciências e tecnologia Fluminense de Campos dos Goytacazes / RJ

2. É ponto pacífico que a relação entre as grandes empreiteiras e o Estado Nacional envolve um histórico de corrupção, lobbies e favorecimentos diversos desde a Ditadura Militar, atravessando os governos independentemente da filiação partidário-ideológica. Vincular tais atos de corrupção 
aos governos do PT foi claramente uma estratégia midiático-golpista. Sobre as relações políticoeconômicas entre as empreiteiras e a ditadura civil-militar brasileira, consultar: CAMPOS, Pedro Henrique Pedreira. 'Estranhas Catedrais': as empreiteiras brasileiras e a ditadura civil-militar, 1964-1988. Niterói: Eduff, 2014.

3. Consultar http://g1.globo.com/economia/seu-dinheiro/noticia/salario-minimo-nao-temaumento-acima-da-inflacao-pela-1-vez-em-13-anos.ghtml?

utm_source=facebook\&utm_medium=share-bar-smart\&utm_campaign=share-bar.

\section{AUTORES}

\section{DESIRÉE GUICHARD FREIRE}

Professora do Departamento de Geografia da FFP-UERJ e do Programa de Pós-Graduação em Geografia da FFP-UERJ desireeuerj@gmail.com

\section{FLORIANO JOSÉ GODINHO DE OLIVEIRA}

Professor Associado e Procientista da Universidade do Estado do Rio de Janeiro, com Pósdoutorado na Universidad de Barcelona. Coordenador do Programa de Pós Graduação em Políticas Públicas e Formação Humana (PPFH/UERJ) e Professor do Programa de Pós-Graduação em Geografia da FFP-UERJ. Coordenador do GT CLACSO Espoliação imobiliária e crítica contra hegemônica e do Grupo de Pesquisa Espaço e Economia do CNPq. fgodinho@uerj.br

\section{GUILHERME RIBEIRO}

Doutor em Geografia pela Universidade Federal Fluminense, com doutorado sandwich pela Universidade de Paris - Sorbonne (Paris IV). Pós-Doutor em Geografia pela Universidade Federal de Minas Gerais. Professor do Programa de Pós-Graduação em Geografia da Universidade Federal Rural do Rio de Janeiro. E-mail: geofilos@msn.com

\section{LEANDRO DIAS DE OLIVEIRA}

Doutor em Geografia pela UNICAMP - Universidade Estadual de Campinas, Mestre e Licenciado em Geografia pela UERJ - Universidade do Estado do Rio de Janeiro. Professor do Programa de Pós-Graduação em Geografia [PPGGEO / UFRRJ] e de Geografia Econômica e da Indústria do Departamento de Geociências da UFRRJ - Universidade Federal Rural do Rio de Janeiro. Coordenador do LAGEPPE - Laboratório de Geografia Econômica e Política e Práticas Educativas. Coordenador do PIBID [Programa Institucional de Bolsa de Iniciação à Docência] - Geografia UFRRJ. E-mails: ldiasufrrj@gmail.com / leandrodias@ufrrj.br 